\title{
A NEW TOOL FOR MODULAR MODELLING: THE GENERALISED AND SYNCHRONISED STOCHASTIC PETRI NETS
}

\author{
O.DANIEL, Z.SIMEU-ABAZI, B.DESCOTES-GENON \\ LAG-ENSIEG, BP 46, 38402 Saint Martin d'Hères CEDEX, FRANCE \\ Tél: +33768264 15, Fax: +3376826388 \\ e-mail:abazi@lag.grenet.fr
}

\begin{abstract}
The association between Stochastic Petri Nets and Markov chains constitute a powerful tool to perform a manufacturing system analysis. Unfortunately, the markovian's models obtained for complex manufacturing systems are so large (combinatory explosion) that their storage and analysis are very expensive and very long. To contain this explosion we are interested in modular modelling This paper deals with a new tool call Generalised and Synchronised Stochastic Petri Nets (GS2PNs).

\section{Keywords}

Stochastic Petri Nets, Decomposition, Modular modelling, Model reduction, manufacturing systems.
\end{abstract}

\section{INTRODUCTION}

The models obtained for large and complex systems are often very heavy. Thus, they loose one of the most important advantage of Petri Nets which is the readability. Some tools like Coloured Petri Nets have been developed in Jensen $(1981,1982,1983)$, and authorise to make a strong reduction of the number of places and transitions of the models. This sort of Petri Nets is very efficient to decrease the system's structural complexity but doesn't simplify their analysis. Another very important point for the markovian analysis that we want to realise is that we need to generate the marking graph of the Petri Net model which is often very large. The continuous Petri Nets developed by R.David and H.Alla in David (1987, 1988, 1989) bring an answer for combinatory explosion. In this sort of nets the number of tokens in a place can be a real and not only an integer. The interest of this tool is that we don't build a marking graph but an evolution graph which is smaller. The continuous Petri Nets offer an interesting answer to states combinatory explosion but, at the moment, they don't provide any way to 
perform an analysis. Our aim is to develop a tool based on SPNs and that authorises modular modelisation.

\section{THE GS ${ }^{2}$ PNS - DEFINITIONS}

The idea of decomposition as already been wildly explored. Many studies have yet been realised on that topic by Beounes (1984), Noyes (1987) or Jungnitz (1992).

The approach that we propose is different because it doesn't generate decomposable models but directly decomposed systems. Furthermore, our decomposition is not structural but functional.

\section{Definition 2.1}

Let $R=\left\{R_{1}, R_{2}, \ldots, R_{t}\right\}$ a set of GSPNs.

$R$ is a GS 2 PN if $\forall i \in\{1,2, \ldots, t\}$ then:

- $\mathrm{Ri}=<\mathrm{P}_{\mathrm{i}}, \mathrm{T}_{\mathbf{i}}$, Pré $_{\mathrm{i}}$, Post $_{\mathbf{i}}, \mathrm{M0}_{\mathrm{i}}$, temp $\mathrm{i}$, ! $\mathrm{S}_{\mathrm{i}}$, ? $\mathrm{S}_{\mathrm{i}}>$ where:

- $\mathrm{Pi}=\left\{\mathrm{P}_{1 \mathrm{i}}, \mathrm{P}_{2 \mathrm{i}}, \ldots, \mathrm{P}_{n i}\right\}$, finite set of places of $\mathrm{R}_{\mathbf{i}}$ with $\left|\mathrm{P}_{\mathbf{i}}\right|=\mathrm{n}_{\mathbf{i}}$.

- $\mathrm{Ti}=\left\{\mathrm{T}_{1 \mathrm{i}}, \mathrm{T}_{2 \mathrm{i}}, \ldots, \mathrm{P}_{\mathrm{mi}}\right\}$, finite set of transitions of $\mathrm{R}_{\mathrm{i}}$ with $\left|\mathrm{T}_{\mathrm{i}}\right|=\mathrm{m}_{\mathbf{i}}$.

- Préi $=\mathrm{Pi} \times \mathrm{Ti} \rightarrow\{0,1\}$.

- $\operatorname{posti}=\mathrm{Ti} \times \mathrm{Pi} \rightarrow\{0,1\}$.

- $\mathrm{MO}_{\mathrm{i}}=\left(\mathrm{MO}\left(\mathrm{P} 1_{\mathbf{i}}\right), \mathrm{M} 0\left(\mathrm{P} 2_{\mathbf{i}}\right), \ldots, \mathrm{M} 0\left(\mathrm{Pn}_{\mathbf{i}}\right)\right)$ the initial marking of $\mathbf{R}_{\mathbf{i}}$.

- tempi $=\left\{\lambda 1_{i}, \lambda 2_{i}, \ldots \lambda m_{i}\right\}$ set of temporisations associated to the transitions of $R_{\mathbf{i}}$.

- $! S_{i}=$ set of synchronisation signals sent by $R_{i}$.

- $? S_{\mathrm{i}}=$ set of synchronisation signals awaited by $\mathrm{R}_{\mathbf{i}}$.

with:

$(\mathrm{P} 1 \cap \mathrm{P} 2 \cap \ldots \cap \mathrm{Pt})=\varnothing$.

$(\mathrm{T} 1 \cap \mathrm{T} 2 \ldots \cap \mathrm{Tt})=\varnothing$.

$(\mathrm{P} 1 \cup \mathrm{P2} \ldots \cup \mathrm{Pt})=\mathrm{P}$ the set of places of $\mathrm{R}$.

$\mathrm{T} 1 \cup \mathrm{T} 2 \cup \ldots \cup \mathrm{Tt}=\mathrm{T}$ the set of transitions of $\mathrm{R}$.

The signals are sent by places when they contain one token (or more) and are received by transitions. Thus, we can find four sorts of transitions which are shared into the following four sets:

- Tin $=\{$ immediate and not synchronised transitions $\}$.

- $T t n=\{$ timed and not synchronised transitions $\}$.

- Tis=\{immediate and synchronised transitions.

- $T t s=\{$ timed and synchronised transitions $\}$.

We shall represent immediate transitions with an horizontal line and timed transition with an horizontal thick bar.

\section{Definition 2.2}

A synchronised transition is authorised if the synchronisation signal that it waits for is present. 


\section{Definition 2.3}

A no synchronised transition is firable if and only if it's validated.

\section{Definition 2.4}

A synchronised transition is firable if it's both validated and authorised.

As mentioned above, the places send the signals which will be received by the transitions.

\section{Definition 2.5}

We shall call « sending place », any place which occupation by at least one token induces the emission of a signal.

\section{Example 2.1}

The place Pi of net of the picture 2.1 is a sending place.

\section{Definition 2.6}

We shall call "receptive transition" or "synchronised transition", any transition which firing is linked to the presence of a synchronisation signal.

\section{Example 2.2}

The transition Tj of the net of the picture 2.1 is receptive.

Graphically, the emission (reception) of a signal by a place (transition) will be represented with a broken arrow leaving (arriving) the place (on the transition<smiles>[M]C1CC(C)C(C)C1C</smiles>

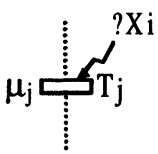

Picture 2.1 Emission of $\mathrm{Xi}$ by $\mathrm{Pi}$, reception of $\mathrm{Xi}$ by $\mathrm{Tj}$

Thus, let consider a GS 2 PN R constituted by two GSPNs R1 and R2. Some transitions of R2 are synchronised with signals sent by places of $R 1$ and vice versa. We can remark that the sending places of R1 (R2) are the ones which marking influence the evolution of R2 (R1).

\section{EVOLUTION RULES AND ALGORITHM}

The problems linked to the modelisation with GS 2 PNs are principally encountered when trying to interpret the conflicts. For classical GSPNs, the only problematic case is the one for which many immediate transitions are simultaneously validated. The GS 2 PNs are quite similar. If in the conflict are implied only transitions $\in$ Tin, then they are required to belong to the same net (we'll say «internal conflict») and, the conflict can be solved by the classical way which consists in using priorities or switching distributions (see Marsan (1984) or Marsan (1987)). If in the conflict appear some immediate and synchronised transitions, two ways are possible: 
- If the conflict concerns transitions of the same net, there is an internal conflict (see above).

- If the conflict concerns transitions from many different nets we'll speak then of « extended conflict $»$.

The extended conflicts are more difficult to solve. The picture 3.1 shows an example of an extended conflict.

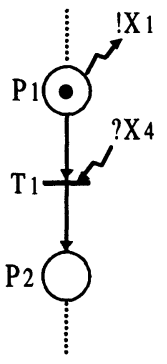

R1

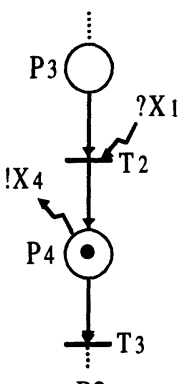

R2

Picture 3.1 Extended conflict

This system represents two GSPNs (R1 and R2) synchronised by a send receive. $R 2$ waits for a message from $\mathrm{R} 1$ (X1) to go on with its evolution. $\mathrm{R} 1$ after the emission of $\mathrm{X} 1$ waits for the answer from R2 (X4).

Let suppose that a token is deposed in P3. Transition T2 is then validated but not authorised because signal X1 is not present. Therefore, if a token is deposed in P1, signal X1 is sent and $\mathrm{T} 2$ is then authorised. We fire T2 and we reach the marking P1P4. There is here an extended conflict between $\mathrm{T} 1$ and $\mathrm{T} 3$. In fact, if we fire T3 first then the emission of signal X4 will be stopped and transition T1 will be unauthorised. On the other hand, if we fire T1 first then transition T3 is still firable. To solve this sort of conflict we will use the VFP interpretation which has been proposed in Jacot (1992). This interpretation consists in making the balancesheet between the tokens produced and consumed by the firing of the transitions in conflict. If this balance-sheet is positive or null then we can fire all the transitions simultaneously. Thus if two transitions are in conflict and if one of them is a reading transition, then the VFP interpretation authorises to fire them simultaneously (see picture 3.2).

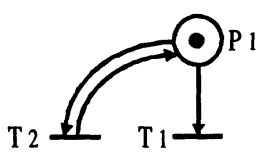

Picture 3.2 Conflict which needs the VFP interpretation

In the picture 3.2, transitions T1 and T2 are in conflict. T2 takes a token in P1 and puts it back at once (balance-sheet $=0$ ). T1 consumes one token (balance-sheet $=-1$ ). The global balancesheet is: $0-1=-1$ and there is just one token in $P 1$. This way, we can fire $\mathrm{T} 1$ and $\mathrm{T} 2$ simultaneously. 
Now, let observe the effect of this interpretation on the GS 2 PNs. The conflict of picture 3.1 may be seen as following.

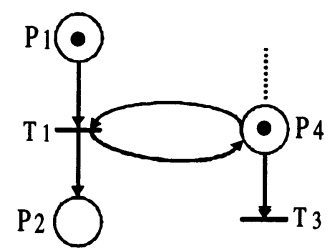

Picture 3.3 conflict of picture 3.1 with classical PN's

In fact, the synchronisation signal X4 corresponds to a reading of the contents of place P4 by transition T1. The VFP interpretation authorises us to fire T1 and T3 simultaneously.

\section{Definition 3.1}

In the case of an external conflict, and according to the VFP interpretation, we fire simultaneously all the transitions.

Picture 3.4 shows another case of conflict that can be solve with the VFP interpretation.<smiles>[Y4]CCc1cc(C)cc(C(C)([AlH])CC[X])c1</smiles>

!X2

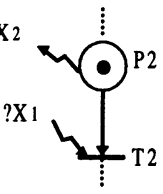

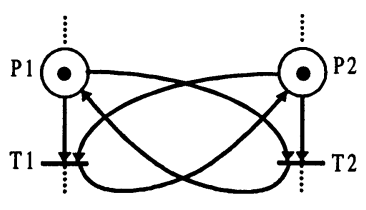

b

Picture 3.4 A conflict a: with GS2PNs, b: with PN's

$\mathrm{X} 1$ represents the reading of the contents of $\mathrm{P} 1$ by $\mathrm{T} 2$ and $\mathrm{X} 2$ is the reading of the contents of $\mathrm{P} 2$ by $\mathrm{T} 1$. $\mathrm{T} 1$ consumes one token (balance-sheet $=-1$ ) and $\mathrm{T} 2$ consumes one token too (balance-sheet $=-1$ ). The global balance-sheet is: $-1-1=-2$ and we dispose of exactly two tokens. Thus, we can fire simultaneously $\mathrm{T} 1$ and $\mathrm{T} 2$.

Picture 3.5 shows an other case of conflict that the VFP interpretation can't solve.

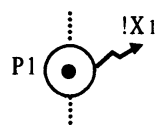

process 1

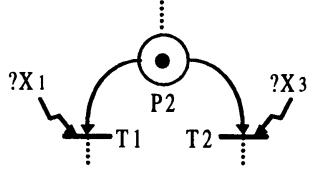

resource

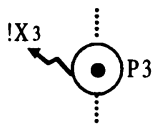

process 2

Picture 3.5 Other sort of conflict

This case is the resource share. Two processes require the same resource and create a conflict between. The global balance sheet of this configuration is negative and we can't fire $\mathrm{T} 1$ and $\mathrm{T} 2$ simultaneously. Fortunately, $\mathrm{T} 1$ and $\mathrm{T} 2$ belong to the same net and the conflict is an internal conflict that we can solve by using switching distributions. 
Now, let see the GS 2 PNs evolution rules.

A GS 2 PN possesses two sorts of markings which are «tangible markings » and "wanishing markings ». According to the sort of marking is the system in, we shall have two sorts of emitted signals. If the system is in a vanishing marking the emitted signal will be a pulse (Dirac $\delta(t))$. If the system is in a tangible state, the emitted signal is a rectangular signal (Heaviside $\mathrm{H}(\mathrm{t})$ ) that endures till there are no more tokens in the concerned places.

\section{Definition 3.2}

The reception of a « pulse signal » by a transition authorises the passage of only one token.

The evolution of a GS $2 \mathrm{PN}$ is subject to the three following rules.

R1: If a marking $M$ validate only timed transitions we use the same evolutions rules than for classical SPNs.

R2: If a marking $M$ validate only immediate transitions, we fire them simultaneously after solving the external and internal conflicts.

R3: If a marking $\mathbf{M}$ validate both timed and immediate transitions, we consider only the immediate ones and then apply the rule $\mathrm{R} 2$.

\section{Remark 3.1}

A signal received by a transition can be a logical combination of signals emitted by others nets.

The picture 3.6 shows three examples of signals logical combinations

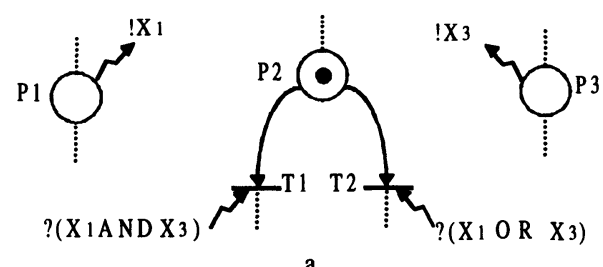

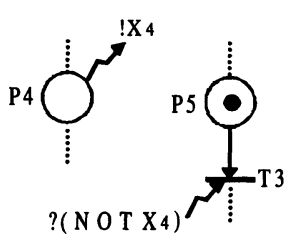

b

Picture 3.6 Logical combinations of synchronisations signals

For the picture $3.6 \mathrm{a}, \mathrm{T} 1$ will be fired if the signals $\mathrm{X} 1$ and $\mathrm{X} 3$ are simultaneously present and $\mathrm{T} 2$ will be fired if $\mathrm{X} 1$ or $\mathrm{X} 3$ is present. Notice that if $\mathrm{X} 1$ and $\mathrm{X} 3$ are simultaneously present, there will be an internal conflict that we solve by using a switching distribution. For example, a switching distribution should be:

$$
\operatorname{Pr}\{\text { fire } T 1=1 / 3\} \quad \operatorname{Pr}\{\text { fire } T 2=2 / 3\}
$$

The picture 3.7 give some equivalencies between GS2PNs and classical PNs. 

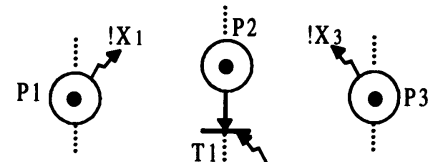

$?(\mathrm{X} 1 \mathrm{E} \mathrm{T} \mathrm{X} 3)$
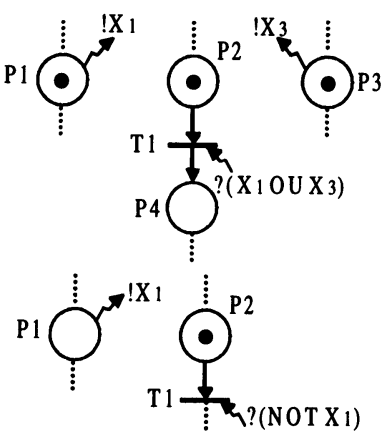
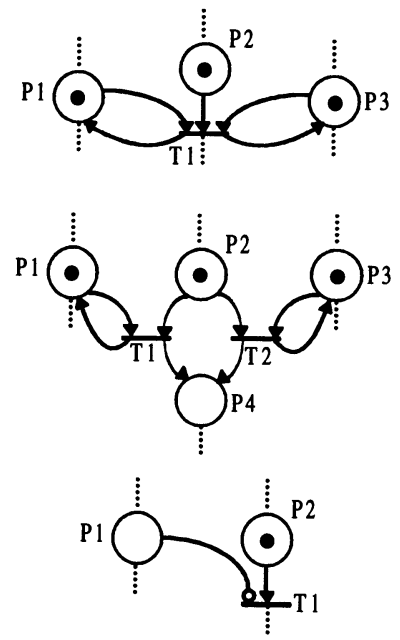

Picture 3.7 Equivalencies between GS2PNs and classical PNs

The following algorithm is the interpretation algorithm for the GS 2 PNs.

\section{ALGORITHM I}

step 1 : Build list $L 1$ of transitions $\in\{$ Tin $\cup$ Ttn $\}$ and which are validated for $M$.

step2 : Build the list $L 2$ of transitions $\in\{$ Tis $\cup$ ts $\}$ and which are validated for $M$.

step 3 : Build list L3 of transitions $\in\{$ Tis $\cup$ Tts $\}$ and which are authorised for M.

step4 : Build $\mathrm{L} 4=\mathrm{L} 2 \cap \mathrm{L} 3$ the list of transitions $\in\{\mathrm{Tis} \cup \mathrm{Tts}\}$ and which are both validated and authorised for $M$.

step5 : Build L5 = L1 $\cup \mathrm{L} 4$ the list of all the transitions which are firable for $\mathrm{M}$.

step6:If L5 contains both immediate and timed transitions then consider only the immediate ones. Apply rule R3 and obtain:

$$
\text { L6 = L5 }-\{\mathrm{Ti} / \mathrm{Ti} \in\{\{\mathrm{Ttn} \cup \mathrm{Tts}\} \cap \mathrm{L} 5\}\}
$$

step7 : Solve the conflicts between transitions in the list L6. We obtain L7 the list of firable transitions.

step8 : Firing of all the transitions with the rules mentioned above.

step9 : Return to step1.

\section{FUNDAMENTAL EQUATION}

The classical PNs have got their fundamental equation that realise the iring. But, what about GS2PNs We shall work on the following GS 2 PN. 


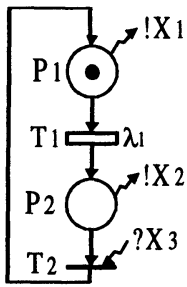

R1

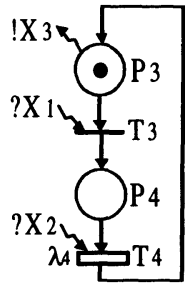

R2

Picture 4.1 Example of GS2PN

Let $\mathrm{R}$ a GS $2 \mathrm{PN}$ composed by two GSPNs R1 and R2. The incidence matrix W and the initial marking $\mathrm{M} 0$ are given:

$$
\mathrm{W}=\left[\begin{array}{rrrr}
-1 & 1 & 0 & 0 \\
1 & -1 & 0 & 0 \\
0 & 0 & -1 & 1 \\
0 & 0 & 1 & -1
\end{array}\right] \quad \mathrm{M} 0=\left[\begin{array}{l}
1 \\
0 \\
1 \\
0
\end{array}\right]
$$

Let apply the algorithm I:

$$
\begin{array}{ll}
\text { step1: } & \mathrm{L} 1=\{\mathrm{T} 1\} \\
\text { step2: } & \mathrm{L} 2=\{\mathrm{T} 3\} \\
\text { step3: } & \mathrm{L} 3=\{\mathrm{T} 3\} \\
\text { step4: } & \mathrm{L} 4=\mathrm{L} 2 \cap \mathrm{L} 3=\{\mathrm{T} 3\} \\
\text { step5: } & \mathrm{L} 5=\mathrm{L} 1 \cup \mathrm{L} 4=\{\mathrm{T} 1, \mathrm{~T} 3\} \\
\text { step6: } & \mathrm{L} 6=\mathrm{L} 5-\{\mathrm{T} 1\}=\{\mathrm{T} 3\} \\
\text { step7: } & \text { No conflicts. } \mathrm{L} 7=\mathrm{L} 6=\{\mathrm{T} 3\} \\
\text { step8: } & \text { The new marking is calculated by firing T3 and is P1P4. }
\end{array}
$$

The incidence matrix is diagonal by blocks. Each block represents one of the two nets constituting R. M0 is also constituted by two blocks which each one represents the initial marking of one of the two nets constituting $\mathrm{R}$. We notice that the ith block of the incidence matrix and the ith block of the marking corresponds both to the same net Ri. Let apply the classical PN's fundamental equation to $\mathrm{W}$ and $\mathrm{M} 0$ with a firing sequence $\mathrm{S}^{\mathrm{T}}=\left[\begin{array}{llll}0 & 0 & 1 & 0\end{array}\right]$ (firing of T3). We notice that the firing sequence $\mathrm{S}^{\mathrm{T}}$ is also constituted by blocks.

$$
\mathrm{M} 1=\mathrm{M} 0+\mathrm{W} \cdot \mathrm{S}=\left[\begin{array}{l}
1 \\
0 \\
1 \\
0
\end{array}\right]+\left[\begin{array}{rrrr}
-1 & 1 & 0 & 0 \\
1 & -1 & 0 & 0 \\
0 & 0 & -1 & 1 \\
0 & 0 & 1 & -1
\end{array}\right] \cdot\left[\begin{array}{l}
0 \\
0 \\
1 \\
0
\end{array}\right]=\left[\begin{array}{l}
1 \\
0 \\
1 \\
0
\end{array}\right]+\left[\begin{array}{r}
0 \\
0 \\
-1 \\
1
\end{array}\right]=\left[\begin{array}{l}
1 \\
0 \\
0 \\
1
\end{array}\right]
$$

We find, without any surprise, exactly the previous result. The classical PNs' fundamental equation can always be used and we can generalise this result to a GS 2 PN constituted by $t$ GSPNs.

This result is interesting but, isn't it possible to take advantage of the modular nature of the 
GS 2 PNs to find an adapted and more rapid fundamental equation?

Let realise the same calculus but on R1 and R2 separately. Let evaluate M11 and M12 the markings reached by $\mathrm{R} 1$ and $\mathrm{R} 2$ after the firing of $\mathrm{T} 3$. The incidence matrix and the initial markings of $R 1$ and $R 2$ are given:

$$
\begin{array}{cc}
\mathrm{W} 1=\left[\begin{array}{rr}
-1 & 1 \\
1 & -1
\end{array}\right] & \mathrm{W} 2=\left[\begin{array}{rr}
-1 & 1 \\
1 & -1
\end{array}\right] \\
\mathrm{M} 01=\left[\begin{array}{l}
1 \\
0
\end{array}\right] & \mathrm{M} 02=\left[\begin{array}{l}
1 \\
0
\end{array}\right]
\end{array}
$$

The new marking can be evaluate separately because R1 and R2 are two classical PNs. As T3 belongs to $R 2$, the two firing sequences $S 1$ and $S 2$ that we must apply to $R 1$ and $R 2$ are respectively $s_{1}^{T}=[0,0]$ and $s_{2}^{T}=[1,0]$. Thus, we obtain:

$$
\begin{aligned}
& \mathrm{M} 11=\mathrm{M} 01+\mathrm{W} 1 \cdot \mathrm{S} 1=\left[\begin{array}{l}
1 \\
0
\end{array}\right]+\left[\begin{array}{rr}
-1 & 1 \\
1 & -1
\end{array}\right] \cdot\left[\begin{array}{l}
0 \\
0
\end{array}\right]=\left[\begin{array}{l}
1 \\
0
\end{array}\right]=\mathrm{M} 01 \\
& \mathrm{M} 11=\mathrm{M} 01+\mathrm{W} 1 \cdot \mathrm{S} 1=\left[\begin{array}{l}
1 \\
0
\end{array}\right]+\left[\begin{array}{rr}
-1 & 1 \\
1 & -1
\end{array}\right] \cdot\left[\begin{array}{l}
0 \\
0
\end{array}\right]=\left[\begin{array}{l}
1 \\
0
\end{array}\right]=\mathrm{M} 01
\end{aligned}
$$

This new marking is the one that we expected. The calculation of the successive markings reached by the GS 2 PN R can be realised by using the classical fundamental equation on each net separately. This result is more interesting than the previous one. In fact, it is more efficient and simple to apply the classical fundamental equation on $r(r \leq t)$ little nets $\left(\mathrm{n}_{\mathrm{i}} \times \mathrm{m}_{\mathrm{i}}\right)$ than on a big one $\left(\sum_{\mathrm{i}=1}^{\mathrm{t}} \mathrm{n}_{\mathrm{i}} \times \sum_{\mathrm{i}=1}^{\mathrm{t}} \mathrm{m}_{\mathrm{i}}\right)$. Furthermore, and practically, the fundamental equation is applied less than $r$ times. In fact, the markings of the nets for which no transitions are fired are not modified. We shall not consider them.

\section{Definition 4.1}

If a GS $2 \mathrm{PN}$ is constituted by $t$ nets then we shall say that its order is $t$ and we shall talk about t-GS 2 PN.

\section{Property 4.1}

Let $R$ be a t-GS2PN.

$\left\{\begin{array}{l}n_{i} \text { the number of places of } \mathrm{Ri} \\ \mathrm{m}_{\mathrm{i}} \text { the number of transitions of } \mathrm{Ri}\end{array}\right\} \mathrm{i} \in(1,2, \ldots, t)$

The step8 of the algorithm 1 can be performed as following:

- Build the firing sequence $\mathrm{Si}$ for each net $\mathrm{Ri}$ as:

$$
\left\{\begin{array}{ll}
S i_{j}=1 & \text { if } T j \in L 7 \\
S i & \text { else }
\end{array}\right\} \text { with } T j \in R i
$$

- Apply the fundamental equation to each net $\mathrm{Ri}$ separately, if at least one element of the firing sequence $\mathrm{Si}$ is positive.

$$
M_{i}^{\prime}=M_{i}+W_{i} \cdot S_{i}
$$




\section{INVARIANTS}

To perform thestructural validation we must prove that each place of the GS $2 \mathrm{PN}$ is bounded and that each transition of the GS $2 \mathrm{PN}$ is alive. This structural validation is usually realised by the research of the p-semi-flots and $t$-semi-flots.

A p-semi-flot is a vector $F(n i \times 1)$ as: $F^{T} \cdot W=0$.

A t-semi-flot is a vector $S(\mathrm{mi} \times 1)$ as: $\mathrm{W} \cdot \mathrm{S}=0$.

We can extract, from the p-semi-flots the list of the bounded places and, from the t-semi-flots the list of the alive transitions. If all the places are bounded we shall say that the net is bounded and if all the transitions are alive we shall say that the net is alive.

for example and for the net of the picture 4.1, if $F^{T}=[f 1 \mathrm{f} 2 \mathrm{f3} f 4]$ and $S^{T}=[s 1 \mathrm{~s} 2 \mathrm{~s} 3 \mathrm{~s} 4]$ then we obtain:

$$
\begin{aligned}
& \mathrm{F}_{1}^{\mathrm{T}}=\left[\begin{array}{llll}
1 & 1 & 0 & 0
\end{array}\right] \text { and } \mathrm{F}_{2}^{\mathrm{T}}=\left[\begin{array}{llll}
0 & 0 & 1 & 1
\end{array}\right] \\
& S_{1}^{T}=\left[\begin{array}{llll}
1 & 1 & 0 & 0
\end{array}\right] \text { and } S_{2}^{T}=\left[\begin{array}{llll}
0 & 0 & 1 & 1
\end{array}\right]
\end{aligned}
$$

We can then extract from F1 and F2 the two following minimal marking invariants:

$$
\left\{\begin{array}{l}
\mathrm{M}(\mathrm{P} 1)+\mathrm{M}(\mathrm{P} 2)=\mathrm{M} 0(\mathrm{P} 1)+\mathrm{M} 0(\mathrm{P} 2)=1 \\
\mathrm{M}(\mathrm{P} 3)+\mathrm{M}(\mathrm{P} 4)=\mathrm{M} 0(\mathrm{P} 3)+\mathrm{M} 0(\mathrm{P} 4)=1
\end{array}\right\}
$$

We can also extract from S1 and S2 the two following minimal firing invariants:

$$
\{\mathrm{T} 1 \mathrm{~T} 2 \text { and } \mathrm{T} 3 \mathrm{~T} 4\}
$$

In the same way that for the fundamental equation, couldn't we use the modular nature of the $\mathrm{GS}^{2} \mathrm{PNs}$ to deduce its invariants from the invariants of its sub-nets?

\subsection{MARKING INVARIANTS}

This calculus is evident for the marking invariants. In fact, as there are no possible transfer of tokens from one sub-net to an other, it is sufficient to prove that each sub-net is bounded.

Let $\mathrm{Fj}$ be a p-semi-flot of the sub-net $\mathrm{Rj}(\mathrm{j} \in(1,2, ., \mathrm{n}))$. It is by definition a column vector (nj $\times 1$ ). Let extend this vector to the GS 2 PN R by addicting $\alpha$ pj zeros above and $\beta p j$ zeros below as:

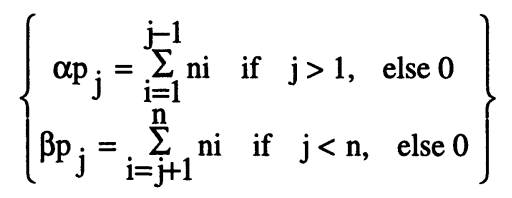

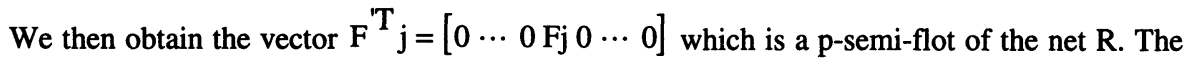
marking invariants of each sub-net $R j$ are also marking invariants of the GS 2 PN $R$ and this 
without any modification.

\section{Example 5.1}

For the GS $2 P N$ of the picture 4.1 the p-semi-flots of $R 1$ and $R 2$ are:

$$
\mathrm{F} 1=\left[\begin{array}{l}
1 \\
1
\end{array}\right] \quad \mathrm{F} 2=\left[\begin{array}{l}
1 \\
1
\end{array}\right]
$$

We extend these two p-semi-flots as explain above and we obtain:

$$
\alpha \mathrm{p}_{1}=0 \quad \text { and } \quad \beta \mathrm{p}_{1}=\sum_{\mathrm{i}=2}^{2} \mathrm{ni}=\mathrm{n} 2=2
$$

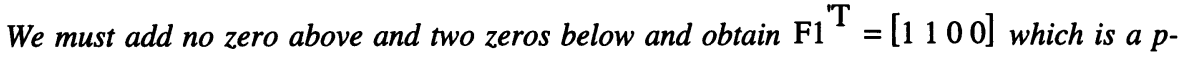
semi-flot of $R$.

$$
\alpha \mathrm{p}_{2}=\sum_{\mathrm{i}=1}^{1} \mathrm{ni}=\mathrm{n} 1=2 \quad \text { and } \quad \beta \mathrm{p}_{2}=0
$$

We must add 2 zeros above and no zero below and obtain $\mathrm{F} 2{ }^{\prime} \mathrm{T}=\left[\begin{array}{llll}0 & 0 & 1 & 1\end{array}\right]$ which is a p-semiflot of $R$.

\subsection{FIRING INVARIANTS}

The search of firing invariants can be perform by applying a similar method than for marking invariants. This method consists in searching the t-semi-flots for each sub-net separately. To each t-semi-flot corresponds a firing invariant of the sub-net. The firing invariants of the GS$^{2} \mathrm{PN}$ are, without any modification, those of its constituting sub-nets.

On an other hand, the GS 2 PN's t-semi-flots are deduced from the sub-nets' t-semi-flots by :

Let $\mathrm{Sj}$ be a t-semi-flot of the sub-net $\mathrm{Rj}(\mathrm{j} \in(1,2, . ., \mathrm{n}))$. It is by definition a column vector $(m j \times 1)$. Let extend this vector to the GS 2 PN $R$ by addicting $\alpha$ tj zeros above and $\beta$ tj zeros below as:

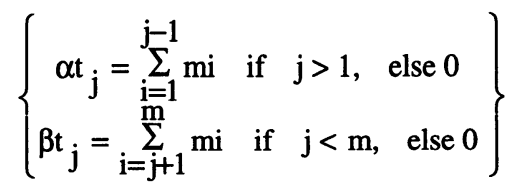

We then obtain the vector $S^{T} j=\left[\begin{array}{llllll}0 & \cdots & 0 & S j & \cdots & 0\end{array}\right]$ which is a t-semi-flot of the net $R$.

Knowing the firing invariants of a GS $2 \mathrm{PN}$ is not enough to prove its vivacity. At the moment, it doesn't exist a mathematical method which prove the vivacity for GS2PNs. So, we propose two necessary conditions which, if they are not verified, prove that a GS 2 PN is not alive.

\section{Necessary condition $n^{\circ} 1$}

To be alive, a GS 2 PN needs necessary that all its constituting sub-nets are alive. The proof of the vivacity of each sub-net can be perform separately by searching its t-semi-flots.

The fact that each sub-net is alive is necessary but not sufficient to prove the vivacity of the GS 2 PN. In fact, it is easy to find some structures that induce problems. The picture 5.1 is one example of this sort of structure that we have named « cross synchronisation ». 

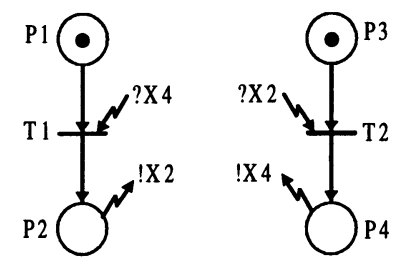

Picture 5.1 Cross synchronisation

The notion of cross synchronisation needs some restrictions. In fact, the fact that the GS 2 PNs of the picture $5.2 \mathrm{a}$ and picture $5.2 \mathrm{~b}$ contain cross synchronisations is not sufficient to affirm that they are dead.

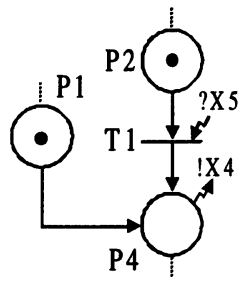

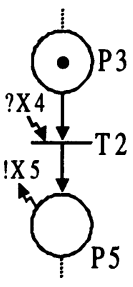

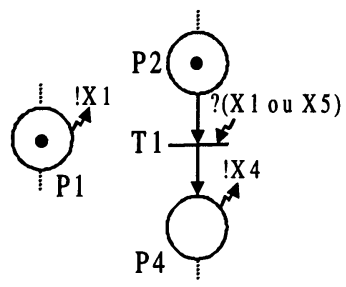

b

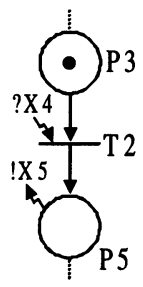

P5

Picture 5.2 Examples of GS2PNs containing cross synchronisations and not necessary deads

Then we introduce,by the following definition, the notion of « strong cross synchronisation ».

\section{Definition 5.1}

A cross synchronisation is called strong if the two following conditions are verified :

1. The places which send of cross synchronisation signals are only filled by the transitions that they lock.

2. The cross synchronisation signals are wether simple or builded with the logical AND of other signals.

We can deduce from this a necessary condition that a GS 2 PN must possess to be alive:

\section{Necessary condition $n^{\circ} 2$}

To be alive, a GS 2 PN must not contain any strong cross synchronisation.

If a GS 2 PN doesn't contain any strong cross synchronisations we can use the same method than for

\section{Example 6.2}

For the GS $2 P N$ of the picture 4.1 the $t$-semi-flots of $R 1$ and $R 2$ are:

$$
\mathrm{S} 1=\left[\begin{array}{l}
1 \\
1
\end{array}\right] \quad \mathrm{S} 2=\left[\begin{array}{l}
1 \\
1
\end{array}\right]
$$

We extend these two t-semi-flots as explain above and we obtain:

$$
\alpha \mathrm{t}_{1}=0 \quad \text { and } \quad \beta \mathrm{t}_{1}=\sum_{\mathrm{i}=2}^{2} \mathrm{mi}=\mathrm{m} 2=2
$$


We must add no zero above and two zeros below and obtain $\mathrm{S} 1^{\mathrm{T}}=\left[\begin{array}{lll}1 & 1 & 0\end{array}\right]$ which is a $t$ semi-flot of $R$.

$$
\alpha \mathrm{t}_{2}=\sum_{\mathrm{i}=1}^{1} \mathrm{mi}=\mathrm{m} 1=2 \quad \text { and } \quad \beta \mathrm{t}_{2}=0
$$

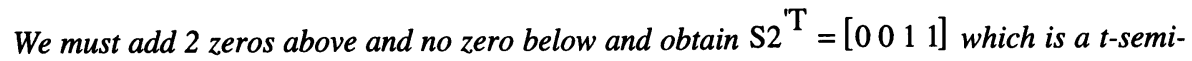
flot of $R$.

The two necessary conditions are verified and it is not possible to affirm (absolutely) that the GS 2 PN of the picture 4.1 is alive. However, the simplicity of this net authorises us to affirm (empiricaly) that it is alive.

\section{BLACK BOX REPRESENTATION}

A GS 2 PN may be seen as constituted by a set of black boxes. Each of those black box contain a GSPN which evolution depends on signals sent by the other black boxes, and sending also synchronisation signals to the other black boxes. The manufacturing systems are well adapted to this sort of representation. In fact, a manufacturing system can be consider as constituted by a set of machines separated by stocks. We have defined generic models for machines and stocks and a manufacturing system can be easily represented with a sort of «construction game ». Generic models for machines an stocks are given by picture $6.1 \mathrm{a}$ and picture $6.1 \mathrm{~b}$.

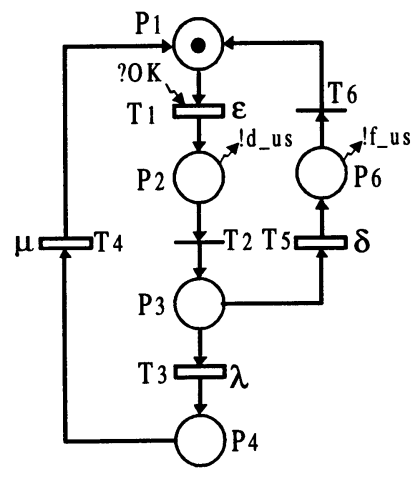

a

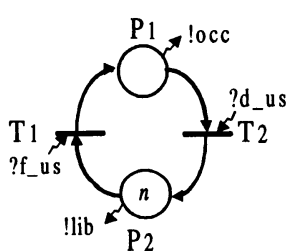

$n=$ stock capacity

b

Picture 6.1 a: generic machine, b: generic stock

The picture $6.2 \mathrm{a}$ and the picture $6.2 \mathrm{~b}$ represent the generic models for machines and stocks as black boxes that can be used to describe any manufacturing system 


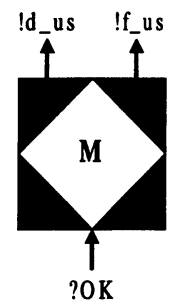

a

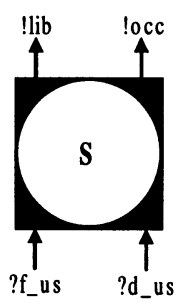

b

Picture 6.2 generic black boxes for, a: machines, b:stocks

This kind of representation authorises to add other generic models for other function like maintenance or rounting scenari.

\section{CONCLUSION}

In this paper is presented a new tool called GS $2 \mathrm{PN}$. This tool is very flexible and authorises a modular description of a system. We can describe each functionality separately and add finally the synchronisations signals.

The evolution rules are simple and more rapid because we work only on little nets and, on an other hand, because only a few sub-nets are concerned for each firing.

The principal reproach with this tool is that we sometimes must add some sets « sending place and immediate transition » to create the emission of a signal. But, to minimise this problem, we must say that the markings thus generate are vanishing markings and don't appear in the marking graph.

We have developed an algorithm which authorises to generate automatically the markovian process of a system describe with GS 2 PNs. The markovian model obtained is also modular and we have developed an iterative algorithm which extracts the RAM's parameters from this representation.

\section{BIBLIOGRAPHY}

Jensen 1981, K.Jensen, « Coloured Petri Nets and the invariant-method » Theorical Computer Science 14, pp 317-336 (1981).

Jensen 1982, K.Jensen, « High level Petri Nets »,third European workshop on application and theory of Petri Nets, Varenna, septembre 1982.

Jensen 1983,K.Jensen, « High level Petri nets », Informatik Fachberichte, vol.66, pp.166-180, 1983

David 1987, R.David, H.Alla, «Continuous Petri nets", 8th European Workshop on application and theory of Petri nets, Saragossa (E), juin 1987.

David 1988], R.David, H.Alla « modelling of productions systems by continuous Petri nets », 3rd Int.conf. CAD/CAM, CARS \& FOF88, Detroit, USA 1988. 
David 1989, R.David, H.Alla: «Du grafcet aux réseaux de Petri ». Traité des nouvelles technologies série Automatique. Hermès 1989.

Beounes 1984, C.Beounes, «Analyse de la sûreté de fonctionnement de systèmes informatiques complexes par réseaux de Petri », rapport de recherche du LAAS n83053 octobre 1983, révisé le 22 novembre 1984.

Noyes 1987, D.Noyes, «Approches méthodologiques pour l'aide à la conception et à la conduite des systèmes de production », Thèse de l'Institut National Polytechnique de toulouse, novembre 1987.

Jungnitz 1992, H.J.Jungnitz, « Approximation methods for stochastic Petri nets », Rensselaer Polytechnique Institute, Electrical, Computer, and Systems Engineering Department Troy, New York 12180-3590, may 1992.

Marsan 1984, M.A.Marsan, G.Conte, and G.Balbo, «A class of generalized stochastic Petri nets for the performance évaluation of multiprocessor systems ». ACM Transactions on computer systems, volume 2, $\mathrm{n}^{\circ} 1, \mathrm{pp} .93-122$, may 1984.

Marsan 1987, M.A.Marsan, G.Balbo, G.Chiola, and G.Conte, «Generalized stochastic Petri nets revisited: random switches and priorities », in proc.int, workshop on Petri nets and performance models, 1987, pp.44-53.

Jacot 1992, L.Jacot, «Les règles de fonctionnement des Réseaux de Petri revisitées et généralisées », LAG, note interne $n^{\circ}$ 92-231, mai 1992 révisée en juillet 1992. 